The figures given in Tables 2 and 3 show that the antibacterial activity is not destroyed by heating for $15 \mathrm{~min}$. to a temperature of $120^{\circ} \mathrm{C}$., the growth-inhibiting properties of the autoclaved extracts (type III), on the contrary, being stronger than those of the corresponding extracts before autoclaving. Furthermore, the substances preventing cell division of Staphylococcus are not held back by the Seit? filter, the antibiotic capacity of a flitered extract of Acer platanoides (type IV) being even greater than that of the untreated extract serving as a control.

TABIE 3. ANTIBIOTIC AOTION EXERTED ON Staphylococcus aureus BY UNDILOTED AND DILUTED IITTER EXTRACTS OF Acer platanoide

\begin{tabular}{|c|c|c|c|c|c|}
\hline \multirow{2}{*}{ Type of extract } & \multicolumn{5}{|c|}{ Dilution } \\
\cline { 2 - 5 } & Undil. & $1: 1$ & $1: 2$ & $1: 3$ & $1: 4$ \\
\hline III & $20 \cdot 6^{6}$ & $18 \cdot 5^{3}$ & $0^{6}$ & $0^{3}$ & $0^{3}$ \\
IIV & $21 \cdot 8^{8}$ & $21 \cdot 5^{3}$ & $18 \cdot 9^{8}$ & $17 \cdot 0^{3}$ & $12 \cdot 3^{3}$ \\
\hline & $21 \cdot 5^{6}$ & $18 \cdot 9^{3}$ & $16 \cdot 7^{6}$ & $15 \cdot 8^{3}$ & $13 \cdot 3^{3}$ \\
\hline
\end{tabular}

In dilution the extracts were mixed with distilled water in the proportions $1: 1,1: 2$, etc. The flgures placed at the top of the mean assay values $(\mathrm{mm}$.$) indicate the number of parallel cylinders used in$ testing.

The results given in Table 3 may be interpreted as indicating that untreated cold water extracts from litter of Acer platanoides contain one or more factors acting as destroying agents upon the antibacteria substances effective against Staphylococcus. This being the case, the inactivator or inactivators involved are susceptible to heat and do not pass through a Seitz fliter, the extracts III and IV, as noticed above. showing a higher capacity to inhibit bacterial growth than does the corresponding extract I.

The antibacterial substances present in litter extracts of Acer platanoides and found to inhibit the growth of Staphylococcus diffuse through 'Cellophane' membranes on dialysing against distilled water.

Finally, it may be worth noting that Osborn' does not range Acer platanoides and Quercus robur with the species of green plants found to be active agairist Staphylococcus aureus when tested as extract from freshly picked material.

\section{ELIAS MELIN}

Institute of Physiological Botany,

TORSTEN WIKÉN

University of Uppsala.

June 16.

1 Melin, E., Symb. Bot. Upsal., 8, 3 (1946).

2 Abraham, E. P., Chain, E., Fletcher, C. M., Florey, H. W., Gardner, A. D., Heatley, N. G., and Jennings, M. A., Lancet, 241, 177 (1941)

' Wikén, T., Ark. Bot., 33, A, 3 (1946), 24 (1943).

Isolation of the Growth-promoting Factor Present in the Fatty Acids of Summer-Butter

IN 1941 Boer and Jansen shrwed ${ }^{1}$ that summer-butter contains a growth-promoting factor that was neither vitamin A nor one of the other known fat-soluble vitamins. Later, Boer and Jansen demonstrated that the growth-promoting action was due to the saponiflable fraction of the summer-butter We have now divided the saponifiable fraction by fractional distillation. The different fatty acids obtained in this way were administered to rats, and the growth of the rats on the different fractions was compared. Details of the technique of this test are given in our earlier publications. In a fuller publication, that will appear elsewhere, the method of distillation also will be described.

It appeared that none of the fractions below $\mathrm{C}_{1}$ had a growth promoting action. However, a fraction near $\mathrm{C}_{10}$, containing only vacoenic acid (it seemed to us very improbable that other substances were present in this fraction), had the same growth-promoting action as summer-butter itself.

Vacoenic acid is an isomer of oleic acid $\left(\mathrm{C}_{17} \mathrm{H}_{33} \mathrm{COOH}\right)$. The double hond, nowever, is here between $\mathrm{C}_{11}$ and $\mathrm{C}_{12}$ (in oleic acid between $\mathrm{C}_{10}$ and $\mathrm{C}_{10}$ ). The vaccenic acid was identifled by its melting point $\left(35^{2} \mathrm{C}.\right)$, and its iodine-value $(81)$.

Thaue 1. First SERIES. Growth DURING 18 DAYS (IN 9TH AND 10Th WEEKS)

\begin{tabular}{|c|c|c|c|}
\hline Litter & Butter & Rape oil & $\begin{array}{c}\text { Rape oil plus } \\
\text { vaccenic acid }\end{array}$ \\
\hline II & 50 & 20 & 41 \\
III & 36 & 33 & 53 \\
IIV & 39 & 37 & 46 \\
VII & 50 & 34 & 43 \\
VII & 63 & 35 & 40 \\
VIII & 45 & 32 & 44 \\
IX & 46 & 34 & 41 \\
XII & 33 & 33 & 42 \\
XII & & 46 & 38 \\
\hline XI & & 34 & 43 \\
\hline
\end{tabular}

TABLe 2. Second series. GRowTH DURING 6TH AND 7TH WeEKS

\begin{tabular}{|c|c|c|c|}
\hline & & & Rape oil plus \\
Litter & Butter & Rape oil & $\begin{array}{c}\text { vaccenic acid } \\
\text { vact }\end{array}$ \\
\hline IV & 62 & 13 & 50 \\
VII & 39 & 35 & 32 \\
VII & 51 & 39 & 48 \\
IX & 47 & 29 & 48 \\
XI & 54 & 27 & $37 / 36$ \\
XII & 33 & 34 & 44 \\
III & 54 & 32 & 35 \\
XI & 33 & 23 & 34 \\
\hline Mean : & 47 & 44 & 53 \\
\hline
\end{tabular}

In two series of experiments, growth of rats on rape oil appeared to be significantly less than the growth on summer-butter. When the fraction of vaccenic acid was added to the rape oil, the difference in growth between rape oil and summer-butter disappeared com-
pletely (Tables 1 and 2 ). Statistical calculation showed that the difference between rape oil and rape oil plus the vaccenic acid fraction is highly significant.

In our opinion, these experiments show that the growth-promoting action of summer-butter is due to the vaccenic acid. A more detailed description of our experiments will be published elsewhere.

$$
\text { J. BOER }
$$

$$
\text { B. C. P. JANSEN }
$$

Netherlands Institute of Nutrition, and A. KENTIE University of Amsterdam.

2 Arch. Nérl. Physio'., 26 (1942).

\section{Liver Glycogen of Alloxan-Diabetic Rats under Different} Conditions

IT is generally agreed that a low glycogen level in liver and muscle is a characteristic of pancreatic diabetes. Considerable importance is attached to this phenomenon in the pathology of diabetes. A similar condition has been observed in alloxan-diabetic rats by Lackey, Bunde, Gill and Harris ${ }^{1}$.

The present communication reports analyses of the liver and muscle glycogen content of alloxan-diabetic rats under different conditions in paired feeding experiments, after a 24-hr. fast period, and after fast combined with additional demands on the carbohydrate meta bolism (muscular work, phloridzin administration). As diabetic animals have a small appetite, liver and musele glycogen were also determined in another experimental series following a fast of $24 \mathrm{hr}$. after prior chronic under-nutrition. The results of these experiments are set forth in the accompanying table.

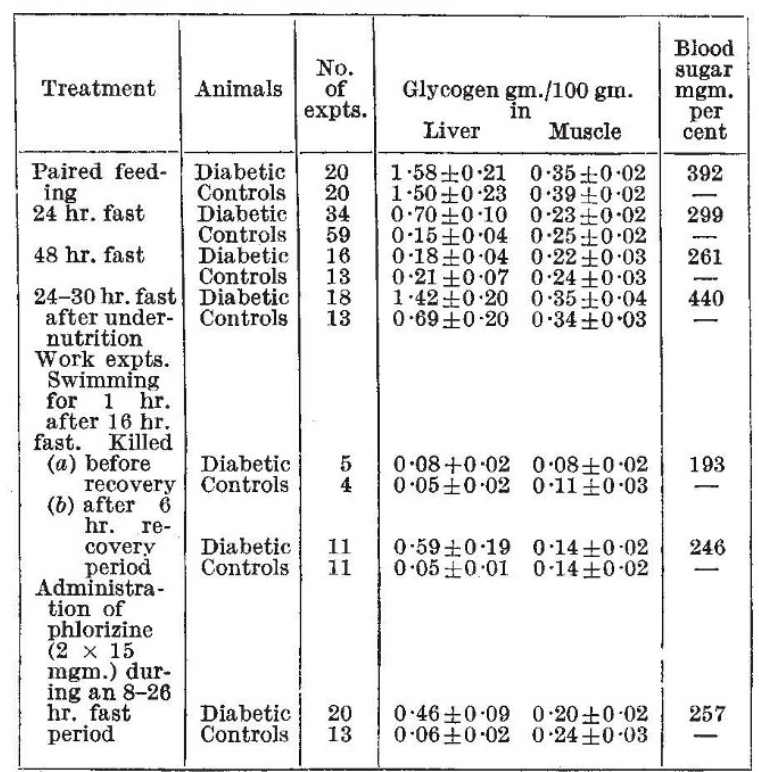

Comatose rats exhibiting marked ketonuria, high blood sugar, high liver fat, deepened breathing, and in general low body temperatur were not included in these experiments, as they show an essentially different behaviour. In ten comatose rats the liver glycogen leve averaged 0.17 per cent, the average blood sugar being $686 \mathrm{mgm}$. per cent. After fasting for $24 \mathrm{hr}$. these rats, in contrast to non-comatose diabetic animals, showed a lower level of liver glycogen than the controls.

The most striking flnding is the existence in alloxan-diabetic rats after a 24-hr. fast-alone or accompanied by additional demands on the carbohydrate reserves - of an increase in level of liver glycogen, 